МОЙСЕСНКО В. І., Д.Т.Н., професор,

ГАСВСЬКИЙ В. В., здобувач кафедри СКС

(Український державний університет залізничного транспорту)

\title{
Оперативна ідентифікація та локалізація небезпек у процесі технічної експлуатації цифрових систем керування рухом поїздів на основі концепції ризик-менеджменту
}

У статті розглядаються проблеми можливості використання та адаптації конщепції ризик-менеджменту для удосконалення технічної експлуатації залізничної автоматики, а саме застосування методів аналізу надійності - методу структурної схеми надійності та марківського аналізу.

Визначено, щчо для реалізачї надання можливості системам IКС 3 А коригувати свою роботу у випадках неякісного технічного обслуговування (ТО) або непідтвердження виконання регламентних дій найбільш доцільним є застосування математичного апарату ланц̧югів Маркова та/або мережі Петрі.

Відповідно до изього способу подання зміни станів системи застосовують методологію аналізу простору станів, щзо є ефективним при дослідженні надійності систем з резервуванням або систем, відмова яких залежить від послідовних подій, або систем зі складними чи багаторівневими стратегіями технічного обслуговування.

Визначено, що більшість елементарних схем, за якими побудовано ІКС 3 А, як $i$ більшість процедур їх роботи, можна подати у вигляді двох елементів, а працездатність системи або окремих ї елементів (програмовані логічні контролери (ПЛК), об'єктні контролери, модулі введення/виведення, канали зв'язку та ін.) залежить від їх стану: працездатного або непрацездатного.

При застосуванні марківського аналізу отримано можливість визначити інтенсивності небезпечних відмов не тільки для изифрової системи керування рухом поӥздів у ціілому, ї̈ окремих вузлів, а $і$ для схем керування елементами топологічного розвитку станції (стрілок, світлофорів, рейкових кіл або системи підрахунку осей та ін.), щчо безпосередньо беруть участь у формуванні та реалізації станиійних маршрутів.

Ключові слова: інформачійно-керуючі системи залізничної автоматики, концепція ризик-менеджменту, метод структурної схеми надійності, марківський аналіз.

\section{Вступ}

Розвиток техніки і технологій у розвинутих країнах за останній час пройшов декілька етапів, що характеризуються якісними та кількісними змінами не тільки техніки, але й уявлень людей. Еволюція розвитку залізничного транспорту також залежить від цих світових тенденцій. Підвищення ефективності експлуатації об'єктів залізничної автоматики повинно досягатися за рахунок зниження витрат матеріальних ресурсів на технічне обслуговування, скорочення обсягу робіт, зменшення потреб у матеріалах, підвищення надійності функціонування, довговічності та безпечності.

При цьому одним 3 важливих питань $є$ ідентифікація та локалізація небезпек у процесі експлуатації цифрових систем керування рухом поїздів: інформаційно-керуючих систем залізничної автоматики (IКС 3А), тому їх дослідження є доцільним та актуальним.

(C) В. І. Мойсеєнко, В. В. Гаєвський, 2020

\section{Постановка проблеми}

Зростаючий показник старіння основних засобів створює додаткові умови для збільшення кількості порушень нормального функціонування систем залізничної автоматики. Існує необхідність визначення критичних значень інтенсивностей цих порушень для процесу використання засобів залізничної автоматики.

Функціонування всіх систем залізничної автоматики пов'язане 3 можливістю виникнення відмов, які по-різному впливають на їхню працездатність. У зв'язку з цим доцільно розглянути питання підвищення безпечності їхньої технічної експлуатації як проведення аналізу ризиків, тобто наскільки часто відбуваються порушення в роботі цифрових системи керування рухом поїздів через відхилення параметрів елементів системи та іншого пов'язаного 3 ним обладнання. Будь-яка IКС ЗА має визначені стадії життєвого циклу від розроблення до утилізації, тому на кожному етапі можна застосовувати різні методи їх оцінювання.

Питання оцінювання ризиків небажаних подій у транспортних процесах $€$ важливим науковим 
завданням. Від його вирішення залежить подальший напрям досліджень щодо підвищення безпечності технічної експлуатації цифрових систем керування рухом поїздів.

\begin{tabular}{l}
\hline Аналіз досліджень та публікацій \\
\hline Більшість досліджень у сфері управління ризиками \\
залізничного транспорту розглядають різні аспекти \\
оцінювання ризиків небажаних подій у транспортних \\
процесах, що безпосередньо пов'язані з управлінням \\
ризиками. Але замало досліджень проводиться в \\
напрямі посилення контролю над незапланованими \\
матеріальними і фінансовими витратами при \\
експлуатації обладнання залізничної автоматики (ЗА), \\
а також зниження збитків від виходу його з ладу. У \\
цьому сенсі управління ризиками потрібно розглядати \\
як логічний і систематичний процес, який можна \\
застосовувати для вибору методів не для подальшого \\
вдосконалення діяльності підприємств, а підвищення \\
ефективності функціонування систем керування рухом \\
поїдів у процесі експлуатації та при проведенні \\
технічного обслуговування (ТО). Загальний підхід, \\
описаний у роботах [1-8], відображує принципи та \\
керівництва для управління будь-якою формою \\
ризиків для будь-якої галузі і будь-якої сфери \\
застосування протягом всього життєвого циклу \\
організації або систем.
\end{tabular}

Відповідно до роботи [9] на залізничному транспорті виділено ризики втрат і збитків, які $\epsilon$ результатом впливу різних суб' єктів, процесів і явищ. Ці ризики класифікуються як:

- природно-кліматичні;

- антропогенні;

- технічні;

- макроекономічні.

Технічні ризики зумовлені технічним станом рухомого складу та залізничної інфраструктури: заводський брак, механічне пошкодження, несправність рухомого складу інфраструктури тощо. Ризики в процесі експлуатації пов'язані з несправністю основних елементів рухомого складу інфраструктури та недостатнім контролем за їхніми властивостями.

Статистика показує, що на залізничному транспорті найрозповсюдженішими є помилки людей разом $з$ поганою організацією перевізного процесу, а частка технічних відмов дуже незначна.

Але дослідження питання взаємопов'язаності технічної та ергатичної складових цих ризиків, на жаль, поки що не знайшло достатнього розвитку серед науковців.

Тому питання адаптації концепції ризикменеджменту для удосконалення технічної експлуатації цифрових систем керування рухом поїздів $\epsilon$ доцільним та актуальним.

\section{Визначення мети та задачі дослідження}

Виходячи 3 вищенаведеного метою дослідження $є$ можливість використання та адаптації концепції ризик-менеджменту:

- для удосконалення технічної експлуатації цифрових систем керування рухом поїздів за рахунок розроблення та удосконалення методів і моделей ідентифікації;

- оцінювання та локалізації небезпечних станів та оперативного визначення технічного стану пристроїв залізничної автоматики з урахуванням особливостей технологічного процесу їх функціонування, технічного обслуговування (ТО) і технологічних робіт, пов'язаних з плановими ремонтами.

\section{Виклад основного матеріалу}

На сьогодні одним 3 основних обмежувальних факторів $\epsilon$ процес старіння основних засобів залізничного транспорту. Якщо взяти до уваги середній строк служби пристроїв залізничної автоматики на рівні 25-30 років, то, вочевидь, щорічне відновлення має бути не меншим $3 \%$. Але навіть цей відносно невеликий відсоток відновлення або омолодження систем не виконується.

Практика експлуатації систем залізничної автоматики свідчить, що зі старінням техніки вона потребує більших витрат часу на відновлення іï властивостей при появі пошкодження. Формалізуючи підходи до моделювання роботи елементів і систем залізничної автоматики, можна виділити серед них такі рівні розроблення моделей.

Рівень 1. Моделювання небезпек, що виникають в окремих частинах систем залізничної автоматики.

Рівень 2. Моделювання роботи систем керування рухом поїздів та окремих елементів систем і елементарних схем керування цих систем.

Основні завдання, які мають вирішуватися моделями:

- визначення найпростіших детермінованих подій 3 невеликою кількістю причин і внутрішніх станів;

- визначення складних детермінованих подій 3 великою кількістю станів;

- визначення подій, що мають стохастичний характер з більшою або меншою кількістю внутрішніх станів.

Виходячи 3 мети дослідження прийнято, що в процесі моделювання для різних рівнів ієрархії має використовуватися різноплановий математичний апарат.

Результати аналізу методів моделювання та математичного апарату, що можуть використовуватись, наведені в табл. 1. 


\begin{tabular}{|l|l|l|}
\hline \multicolumn{1}{|c|}{ Вид моделі } & \multicolumn{1}{|c|}{ Математичний апарат } & \multicolumn{1}{c|}{ Перелік вирішуваних завдань } \\
\hline $\begin{array}{l}\text { Безперервно- } \\
\text { стохастичні }\end{array}$ & Ланцюги Маркова & $\begin{array}{l}\text { Моделювання процесів безпечного використання } \\
\text { засобів автоматики }\end{array}$ \\
\hline Мережеві & Мережі Петрі & $\begin{array}{l}\text { Моделювання поїзної ситуації та нештатних } \\
\text { станів у засобах залізничної автоматики }\end{array}$ \\
\hline
\end{tabular}

Визначено, що для реалізації надання можливості системам ІКС ЗА коригувати свою роботу у випадках неякісного технічного обслуговування (ТО) або непідтвердження виконання регламентних дій з ТО найбільш доцільним є застосування математичного апарату ланцюгів Маркова та/або мережі Петрі.

$$
\text { За міжнародними стандартами }
$$
МЕК 61078. Методи аналізу надійності. Метод структурної схеми надійності [10] та IEC 61165:2006. Application of Markov techniques [11], марківський аналіз застосовують, коли майбутній стан системи залежить тільки від ії поточного стану. Цей метод найбільш доцільно використовувати для аналізу показників функційної безпечності, безвідмовності, ремонтопридатності ІКС ЗА, які можуть працювати в багатьох режимах і ситуаціях, коли застосування аналізу надійності окремих блоків системи $\epsilon$ недоцільним. Залежно від складності цифрових систем керування рухом поїздів метод може бути застосований з використанням більш високого порядку процесів Маркова i обмежений тільки моделлю, математичними обчисленнями і припущеннями.

Марківський аналіз $є$ аналогічним аналізу мережі Петрі за можливістю забезпечення моніторингу та спостереження за станами системи, але, на відміну від мережі Петрі, метод допускає існування декількох станів в один і той самий час [13]. Тому застосування мереж Петрі потребує окремого дослідження та не розглядається в межах цього дослідження.

Процес марківского аналізу є кількісним методом і може бути дискретним (використання ймовірностей переходу між станами) або безперервним (використання коефіцієнтів інтенсивності переходу зі стану в стан) і може бути виконаний з використанням комп'ютерних програм.

Він також використовуеться для систем із різною структурою для розрахування експлуатаційної готовності, включаючи можливість розрахування необхідних компонентів запчастин для ремонту. Діаграми станів і переходів є графічним поданням функціонування системи, що досліджується, і моделює аспекти надійності поведінки системи в часі.

Для проведення марківського аналізу необхідні такі дані:
- перелік різних станів системи, важливих підсистем або компонентів: повне функціонування, часткове функціонування (погіршення стану), відмова;

- точне розуміння можливих переходів, які необхідно змоделювати;

- швидкість переходу з одного стану в інший, що зазвичай подана або ймовірністю переходу для дискретних подій, або інтенсивністю відмов $(\lambda)$ і (або) інтенсивністю відновлення $(\mu)$ для безперервних подій.

У даному дослідженні встановлено припущення: ІКС ЗА розглядається як набір елементів, кожен з яких може існувати тільки в одному з двох станів:

- непрацездатному;

- працездатному.

Система в цілому може існувати в різних станах, кожен 3 яких визначається специфічною комбінацією працездатного і непрацездатного станів її елементів.

Таким чином, у момент відмови або відновлення елемента система переходить 3 одного стану в наступний.

Також встановлено обмеження, що ІКС ЗА, а саме цифрові системи керування рухом поїздів (РПЦ та МПЦ), $\epsilon$ складними системами, що можуть знаходитися в одному з трьох станів:

- працездатному $\left(S_{1}, S_{\mathrm{m}}\right)$;

- погіршеному (частково непрацездатному $S_{2}$, $\left.S_{\text {п.3 }}\right)$

- непрацездатному $\left(\mathrm{S}_{3}, S_{\text {п.н }}\right)$.

Модель, що досліджується, $є$ моделлю дискретних станів 3 безперервним часом.

Відповідно до цього способу подання зміни станів системи застосовують методологію аналізу простору станів, що є ефективною при дослідженні надійності систем 3 резервуванням або систем, відмова яких залежить від послідовних подій, або систем зі складними чи багаторівневими стратегіями технічного обслуговування.

Всі існуючі на сьогодні ІКС ЗА повністю відповідають зазначеним вище визначенням.

У табл. 2 наведено ймовірність того, що в наступний момент часу система буде перебувати в стані $\mathrm{S}_{i}$, де $i$ може бути 1,2 або 3. 
Таблиця 2

Матриця Маркова ІКС 3А

\begin{tabular}{|c|c|c|c|}
\hline $\begin{array}{c}\text { Стан у } \\
\text { наступний } \\
\text { момент часу }\end{array}$ & \multicolumn{3}{|c|}{$\begin{array}{c}\text { Стан у поточний } \\
\text { момент часу }\end{array}$} \\
\cline { 2 - 4 } & $\mathrm{S}_{1}$ & $\mathrm{~S}_{2}$ & $\mathrm{~S}_{3}$ \\
\hline $\mathrm{S}_{1}$ & 0,95 & 0,30 & 0,2 \\
\hline $\mathrm{S}_{2}$ & 0,04 & 0,65 & 0,6 \\
\hline $\mathrm{S}_{3}$ & 0,01 & 0,05 & 0,2 \\
\hline
\end{tabular}

Для отримання цих імовірностей необхідно проаналізувати роботу ІКС ЗА за тривалий період i сформувати необхідну базу даних. Але зараз у практиці експлуатації цифрових систем керування рухом поїздів практично відсутні відмови та відповідно існують обмеження в статистичних даних технічних відмов. Тому для проведення досліджень табл. 2 містить значення ймовірностей, що отримані 3 використанням статистичних даних про експлуатацію класичних (релейних) систем залізничної автоматики [14].

Зважаючи на спільність загальних принципів побудови й процесу функціонування релейноконтактних і мікропроцесорних систем залізничної автоматики вважаємо, що їхня поведінка може бути подана як аналогічні змінні дискретного типу.

Аналогом масиву ймовірностей може бути діаграма Маркова, наведена на рис. 1.

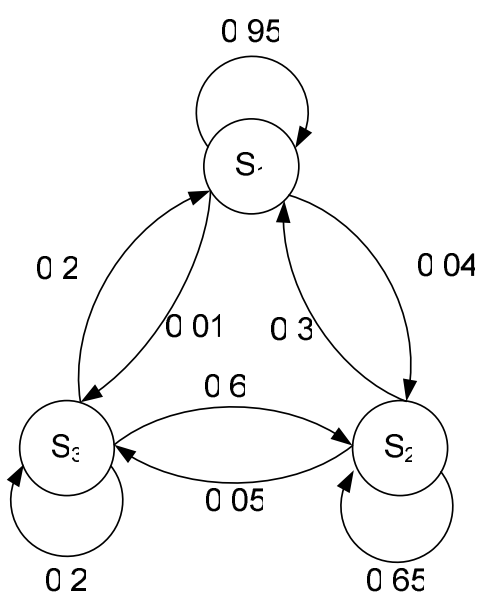

Рис. 1. Діаграма станів і переходів паралельної системи із двох ідентичних елементів

Якщо $\mathrm{P}_{\mathrm{i}}$ - імовірність перебування системи в стані $i$ для $i=1,2,3$, то

$$
\begin{aligned}
& \mathrm{P}_{1}=0,95 \mathrm{P}_{1}+0,30 \mathrm{P}_{2}+0,20 \mathrm{P}_{3} \\
& \mathrm{P}_{2}=0,04 \mathrm{P}_{1}+0,65 \mathrm{P}_{2}+0,60 \mathrm{P}_{3} \\
& \mathrm{P}_{3}=0,01 \mathrm{P}_{1}+0,05 \mathrm{P}_{2}+0,20 \mathrm{P}_{3}
\end{aligned}
$$

Ці три рівняння залежні, оскільки будь-яке рівняння може бути отримано 3 двох інших, і система рівнянь не може бути розв'язана. Для розв'язання необхідно одне 3 наведених рівнянь виключити, замінивши його на

$1=\mathrm{P}_{1}+\mathrm{P}_{2}+\mathrm{P}_{3}$

Отримані після розв'язання значення становлять 0,85; 0,13 і 0,02 відповідно для станів 1, 2, 3, тому можемо зробити проміжний висновок, що система $\epsilon$ повністю функціонуючою протягом $85 \%$ часу, у погіршеному - стані протягом $13 \%$ часу і в стані відмови протягом $2 \%$ часу.

Згідно з EN 50126 [2] технічні принципи для експлуатаційної готовності ІКС грунтуються на відомостях:

- про надійність;

- ремонтопридатність;

- експлуатацію та технічне обслуговування.

Технічні принципи для безпеки у своїй більшості грунтуються на відомостях:

- про всі можливі небезпечні стани системи та показники кожного 3 них при всіх режимах експлуатації, ТО і станах навколишнього середовища;

- відмови, пов'язані з безпекою;

- ймовірності виникнення такої відмови;

- послідовності виникнення подій, відмов, які можуть призвести до аварії;

- ймовірність, $з$ якою кожна 3 цих подій або відмов відбувається;

- ремонтопридатність усіх пов'язаних з безпекою частин системи;

- процес експлуатації системи і ТО з урахуванням впливу людського фактора на ефективне технічне обслуговування;

- ефективний контроль і заходи щодо уникнення небезпечних станів і зменшення їхніх наслідків.

Всі відмови негативно позначаються на надійності системи, однак тільки деякі специфічні відмови мають негативний ефект на безпеку при даному конкретному застосуванні.

Ці зв’язки відображені на рис. 2.

Оскільки більшість елементарних схем, за якими побудовані ІКС залізничної автоматики, як і більшість процедур їх роботи, можна подати у вигляді двох елементів, а працездатність системи або окремих іiі елементів (ПЛК, об'єктні контролери, модулі введення/виведення, канали зв'язку та ін.) залежить від їхнього стану, і вони можуть бути у працездатному або непрацездатному стані, розглядаємо три варіанти:

- стан 1 - обидва елементи знаходяться в працездатному стані;

- стан 2 - один елемент відмовив і знаходиться на відновленні, а інший перебуває в працездатному стані;

- стан 3 - обидва елементи відмовили i знаходяться на відновленні. 


\section{ОТОЧЕННЯ}

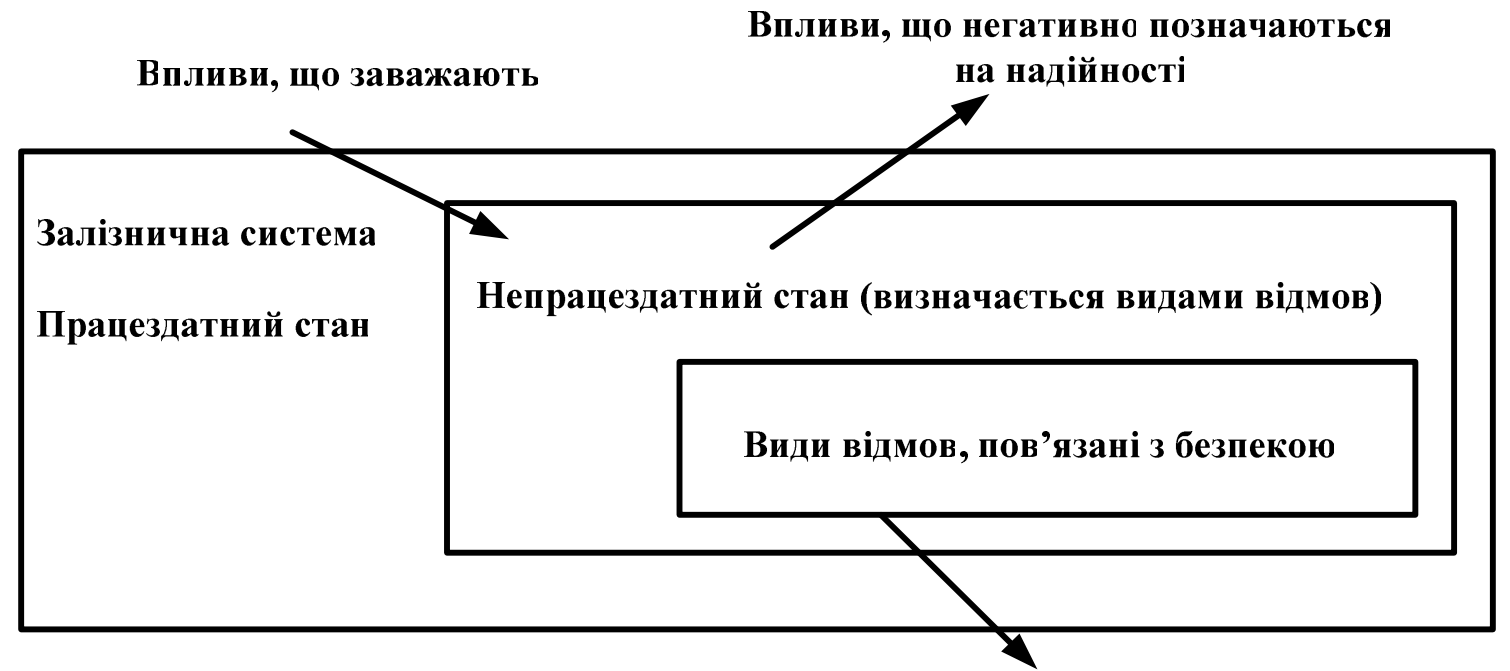

Впливи, що негативно позначаються на безпеці

Рис. 2. Впливи відмов всередині системи

Якщо інтенсивність відмови кожного елемента взяти рівною $\lambda$, а інтенсивність відновлень рівною $\mu, \mathrm{i}$ вони $є$ постійними, то діаграму стану переходу можна подати у вигляді рис. 3.

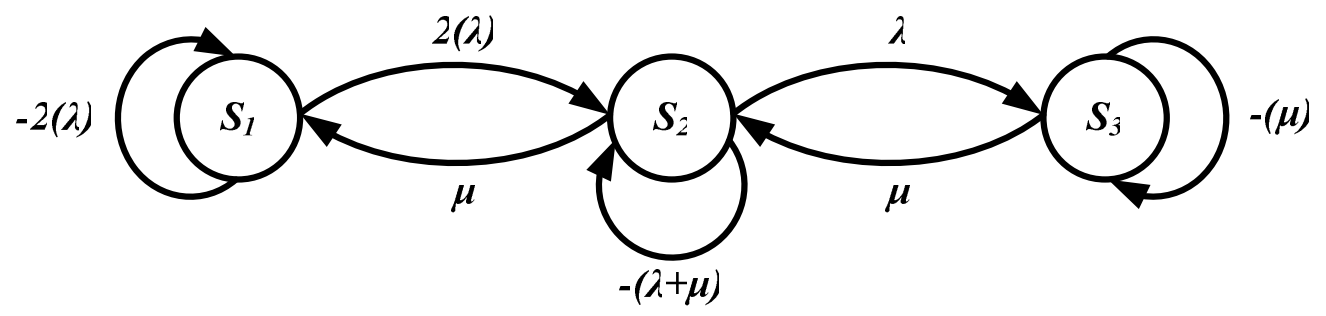

Рис. 3. Діаграми станів переходу

При цьому інтенсивність переходу зі стану 1 в стан 2 дорівнює $2 \lambda$, оскільки відмова будь-якого 3 двох елементів надає системі стану 2.

Приймемо, що $\mathrm{P}_{i}(\mathrm{t})$ - імовірність перебування системи в початковому стані $i$ (де $i=1,2$ та 3 відповідно) у момент часу $\mathrm{t} ; \mathrm{P}_{i}(\mathrm{t}+\delta \mathrm{t})$ - імовірність перебування системи в кінцевому стані в момент часу $(\mathrm{t}+\delta \mathrm{t})$.

Необхідно відзначити, що нульові значення виникають тому, що переходи неможливі зі стану 1 в стан 3 або зі стану 3 у стан 1 . Крім того, сума в колонці дорівнює нулю при визначенні інтенсивності.

У цьому випадку система рівнянь має такий вигляд:
$\mathrm{dP}_{1} / \mathrm{dt}=2 \lambda \mathrm{P}_{1}(\mathrm{t})+\mu \mathrm{P}_{2}(\mathrm{t})$

$d P_{2} / d t=2 \lambda P_{1}(t)+-(\lambda+\mu) P_{2}(t)+\mu P_{3}(t)$,

$\mathrm{dP}_{3} / \mathrm{dt}=\lambda \mathrm{P}_{2}(\mathrm{t})+-\mu \mathrm{P}_{3}(\mathrm{t})$

Для спрощення скористуємося припущенням, що необхідна працездатність відповідає стійкому стану системи.

Для розв'язання цієї системи диференціальних рівнянь для ймовірностей $\mathrm{P}_{1}(\mathrm{t}) ; \quad \mathrm{P}_{2}(\mathrm{t}) ; \quad \mathrm{P}_{3}(\mathrm{t})$ передбачається, що в момент часу $\mathrm{t}=0$ система знаходиться в стані 0, тобто 
$P_{1}(t)=1$

$\mathrm{P}_{2}(\mathrm{t})=0$

$\mathrm{P}_{3}(\mathrm{t})=0$.

У цьому випадку коефіцієнт готовності (функція готовності) $\mathrm{K}_{2}(\mathrm{t})$ розраховується за формулою

$\mathrm{K}_{2}(\mathrm{t})=\mathrm{P}_{1}(\mathrm{t})+\mathrm{P}_{2}(\mathrm{t})$

Якщо $\delta \mathrm{t}$ прямує до нескінченності, a $\mathrm{dP}$ i $/ \mathrm{dt}$ прямує до нуля, і використовуючи додаткове рівняння (4), то можемо спростити рівняння і тоді $\mathrm{K}_{2}(\mathrm{t})=\mathrm{P}_{1}(\mathrm{t})+\mathrm{P}_{2}(\mathrm{t})$ можна записати як

$\mathrm{K}_{2}(\mathrm{t})=(\mu 2+2 \lambda \mu) /(\mu 2+2 \lambda \mu+\lambda 2)$.

Використовуючи ці результати можна розробити кінцеву матрицю Маркова використовуючи інтенсивність відмов $(\lambda)$ та інтенсивність відновлення $(\mu)$, подану в табл. 3.

Таблиця 3

Кінцева матриця Маркова

\begin{tabular}{|c|c|c|c|}
\hline \multirow{2}{*}{$\begin{array}{l}\text { Кінцевий } \\
\text { стан }\end{array}$} & \multicolumn{3}{|c|}{ Початковий стан } \\
\cline { 2 - 4 } & $\mathrm{P}_{1}(\mathrm{t})$ & $\mathrm{P}_{2}(\mathrm{t})$ & $\mathrm{P} 3(\mathrm{t})$ \\
\hline $\mathrm{P}_{1}(\mathrm{t}+\delta \mathrm{t})$ & $-2 \lambda$ & $\mu$ & 0 \\
\hline $\mathrm{P}_{2}(\mathrm{t}+\delta \mathrm{t})$ & $2 \lambda$ & $-(\lambda+\mu)$ & $\mu$ \\
\hline $\mathrm{P}_{3}(\mathrm{t}+\delta \mathrm{t})$ & 0 & $\lambda$ & $-\mu$ \\
\hline
\end{tabular}

Для кількісного та якісного оцінювання надійності (безвідмовності) і безпечності функціонування при відмовах технічних засобів залізничної автоматики використовуються аналітичні методи.

Згідно 3 визначенням показників надійності та функційної безпечності розрахунок виконується 3 урахуванням того, що час безвідмовної (безпечної) роботи підпорядковується експоненціальному розподілу.

Використовуючи розрахунково-логічні схеми елементів існуючих ІКС ЗА і дані $з$ напрацювання на відмову, можна отримати результати розрахунків показників функційної безпечності та безвідмовності ПЛК, об'єктних контролерів стрілок і сигналів (ОКСС), схем управління стрілкою та світлофором, у тому числі і інтенсивність небезпечних відмов $\lambda$, i розглянути інтенсивність відмов компонентів систем не як константу, а як функцію, що збільшується за експоненціальним законом з урахуванням початкових станів інтенсивностей їхніх відмов і параметрів їхніх мінливостей.

\section{Висновки}

При застосуванні концепції ризик-менеджменту, а саме марківського аналізу отримана можливість визначити інтенсивність небезпечних відмов не тільки для ІКС ЗА в цілому та іï̈ окремих вузлів, а і для схем керування елементами топологічного розвитку станції (стрілок, світлофорів, рейкових кіл або системи підрахунку осей та ін.), що безпосередньо беруть участь у формуванні та реалізації станційних маршрутів. Подальшим розвитком цього напряму $\epsilon$ проведення досліджень 3 отримання багатовимірного функціоналу надійності або безпечності для прогнозування станів ІКС ЗА в різних часових точках 3 урахуванням параметрів зношення елементів.

\section{Список використаних джерел}

1. Хенли Э. Д., Кумамото Х. Надежность технических систем и оценка риска: пер. с англ. В. С. Сыромятова, Г. С. Деминой; под общ. ред. В. С. Сыромятова. Москва: Машиностроение, 1984. $528 \mathrm{c}$.

2. Стандарт EN 50126 CENELEC Спецификация и доказательство надежности, эксплуатационной готовности, ремонтнопригодности и безопасности (RAMS) для использования на железных дорогах, $1999.73 \mathrm{c}$.

3. ДСТУ IEC/ISO 31010:2013. Керування ризиком. Методи загального оцінювання ризику (IEC/ISO 31010:2009, IDT)] ДСТУ IEC/ISO 31010:2013. Risk management - Risk assessment techniques (Керування ризиком. Методи загального оцінювання ризику). URL: https://khoda.gov.ua/image/catalog/ files/dstu\%2031010.pdf.

4. Березуцький В. В., Адаменко М. І. Небезпечні виробничі ризики та надійність: навч. посіб. для студ. за напрямком підготовки 6.170202 «Цивільна безпека». Харків: ФОП Панов А. М., 2016. 385 с.

5. Korzeniowski F. Leszek. Securitologia. Nauka o bezpieczenstwie czlowieka i organizcji spolecznych: monografia naukowa. EAS, Krakow, 2008. 311 str.

6. Hofreiter Ladislav, Simko Juraj. Zdroje a oblasti konfliktov sucasneho sveta. Akademia ozbrojenych sil generala Milana Rastislava Stefanika, Liptovsky Mikulas, 2007. 95 str.

7. Запорожець О. I. Щодо проекту концепції управління ризиками надзвичайних ситуацій техногенного і природного характеру // Безпека життя i діяльності людини - освіта, наука, практика. - Київ: Самміт-Книга, 2007. С. 10-12.

8. Медушевський С. Розробка уніфікованої методики оцінки ризиків у процесі валідації автоматизованих інформаційних систем. Технічні науки та технологї: науковий журнал. Чернігів: ЧНТУ, 2018. № 2 (12). С. 151-158. 
9. Ткаченко I. О. Ризики у транспортних процесах: навч. посіб. Харків: ХНУМГ ім. О. М. Бекетова, $2017.114 \mathrm{c}$.

10. IEC 61078 Analysis Techniques for System Reliability. Reliability Block Diagram and Boolean Methods. Edition3.0 2016-08: INTERNATIONAL STANDARD. IEC Central Office Geneva Switzerland. $2016 \quad 116$ p. URL: https://ru.scribd.com/document/102115571/As-IEC61078-2008-Analysis-Techniques-for-SystemReliability-Reliability-Block-Diagram-and-BooleanMethods.

11. IEC 61165-2008 Application of Markov Techniques: INTERNATIONAL STANDARD. IEC Central Office Geneva. Switzerland. 2016. 27 p. URL: https://ru.scribd.com/document/102115630/As-IEC61165-2008-Application-of-Markov-Techniques.

12. ДСТУ ISO/IEC 15909-2:2016. Інженерія програмних засобів і систем. Високорівневі мережі Петрі. Част. 2. Формат передавання (ISO/IEC 15909-2:2011, IDT) // ГП «Украинский научно-исследовательский и учебный центр проблем стандартизации, сертификации и качества (ГП «УкрНИУЦ»). URL: http://online.budstandart.com/ua/catalog/docpage?id_doc $=67174$.

13. ДСТУ ISO/IEC 15909-1:2016. Инженерия программных средств и систем. Высокоуровневые сети Петри. Част. 1. Концепции, определения понятий и графические обозначения. Изменение 1. Симметричные сети (ISO/IEC 15909-1:2004/Amd $1: 2010$, IDT) // ГП «Украинский научноисследовательский и учебный центр проблем стандартизации, сертификации и качества» (ГП «УкрНИУЦ»).

http://online.budstandart.com/ru/catalog/ docpage?id_doc $=79805$.

14. Аналіз стану безпеки руху на залізницях України у 2011 році / О. Мусієнко, О. Ходаковський, С. Ребриков, В. Крот // Державна адміністрація залізничного транспорту України. Київ: Головне Управління Безпеки руху і екології, 2012. 94 с.

\footnotetext{
Моисеенко В. И., Гаевский В. В. Оперативная идентификация и локализация угроз в процессе технической эксплуатации цифровых систем управления движением поездов на основе концепции риск-менеджмента.

Аннотация. В статье рассмотрены проблемы возможности использования и адаптации концепции управления рисками для улучшения технической эксплуатации систем автоматизации железных дорог, а именно применение методов анализа надежности: метода структурной схемы надежности и марковского анализа.
}

Решение вопросов повышения надежности функционирования, долговечности и безопасности эксплуатации цифровых систем управления движением поездов или информационно-управляющих систем железнодорожной автоматики (ИУС ЖДА) становится возможным за счет:

- определения критических значений интенсивности нарушений их нормального функционирования;

- оценки и локализации опасных состояний и оперативного определения технического состояния устройств железнодорожной автоматики с учетом особенностей технологического процесса их эксплуатации, технического обслуживания и технологических работ, связанных с плановыми ремонтами.

Определено, что для реализации возможности систем ИУС ЖДА корректировать свою работу в случаях некачественного проведения технического обслуживания (ТО) или отсутствия подтверждения его выполнения наиболее целесообразно использовать математический аппарат цепей Маркова и/или сети Петри.

Согласно этому методу представления изменений в состояниях системы используется методология анализа пространства состояний, которая эффективна при изучении надежности избыточных систем или систем, отказ которых зависит от последовательных событий, или систем со сложными или многоуровневыми стратегиями обслуживания.

Определено, что большинство элементарных схем, на которых построены ИУС ЖДА, а также большинство процедур их работы могут быть представлены в виде двух элементов, а производительность системы или ее отдельных компонентов (программируемых логических контроллеров (ПЛК), объектных контроллеров, модулей ввода/вывода, каналов связи и т. д.) в зависимости от их состояния и могут быть в работоспособном или неработоспособном состоянии.

При применении марковского анализа можно определить интенсивность опасных отказов не только цифровой системы управления поездов в целом, ее отдельных узлов, но и цепей управления топологическими объектами станции (стрелки, светофоры, рельсовые цепи или система счета осей и т. п.), которые непосредственно участвуют в формировании и реализации станционных маршрутов. Ключевые слова: информационно-управляющие системы автоматизации железных дорог, концепция управления рисками, метод структурной схемы надежности, марковский анализ. 
Moiseienko Valentin, Gaievskyi Vitalii. Operational identification and localization of hazards in the process of technical operation of digital train control systems based on the concept of risk management.

Abstract. The article considers the problems of the possibility of using and adapting the concept of risk management to improve the technical operation of railway automation, namely the application of: methods of reliability analysis - Method of structural scheme of reliability and Markov analysis.

The decision of questions of increase of reliability of functioning, durability and safety of operation of systems of digital systems of management of movement of trains or information - control systems of railway automatic equipment (ICS ZA) becomes possible at the expense of:

- determination of critical values of intensities of violations of their normal functioning;

- assessment and localization of dangerous conditions and prompt determination of the technical condition of railway automation devices, taking into account the peculiarities of the technological process of their operation, maintenance (MA) and technological works related to scheduled repairs.

It is determined that to implement the possibility of ICS ZA systems to adjust their work in cases of poor maintenance (MA) or failure to confirm the implementation of regulatory actions with MA, it is most appropriate to use the mathematical apparatus of Markov circuits and / or Petri nets.

According to this method of representing changes in system states, a state space analysis methodology is used that is effective in studying the reliability of redundant systems or systems whose failure depends on sequential events, or systems with complex or multilevel maintenance strategies.

It is determined that most of the elementary circuits on which ICS ZA is built, as well as most of their procedures, can be represented as two elements, and the performance of the system or its individual elements (programmable logic controllers), object controllers, I/O modules, communication channels, etc.) depends on their condition and may be in working order or inoperable.

When applying the Markov analysis, it is possible to determine the intensity of dangerous failures not only for the digital control system of trains as a whole, its individual nodes, but also for control circuits of the topological development of the station (arrows, traffic lights, rail circuits or axle counting systems, etc.). directly involved in the formation and implementation of station routes.

Key words: information - controlling systems of railway automation, concept of risk management, method of structural scheme of reliability, Markov analysis.
Мойсеснко Валентин Іванович, д.т.н., професор, завідувач кафедри СКС, Украйнський державний університит залізничного транспорту, Харків, Україна. E-mail:mvi53@ukr.net, ORCID ID: https://orcid.org/0000-0003-1377-8703

Гаєвський Вімалій Вікторович, здобувач кафедри СКС, Украӥнський державний університет залізничного транспорту, Харків, Украӥна. E-mail: gaevskiyv54@gmail.com ORCID ID: https://orcid.org/0000-0001-7294-5706.

Moiseienko Valentin, doctor of tech. sciences, chief of chair Specialized Computer Systems, Ukrainian State University of Railway Transport. E-mail: mvi53@ukr.net, ORCID ID: https://orcid.org/0000-0003-1377-8703

Gaievskyi Vitalii, a candidate of cair Specialized Computer Systems Department, Ukrainian State University of Railway Transport, Kharkiv, Ukraine.

E-mail: gaevskiyv54@gmail.com

ORCID ID: https://orcid.org/0000-0001-7294-5706 